\title{
RE-ENERGISING PROFESSIONAL CREATIVITY \\ FROM A CHAT PERSPECTIVE: \\ SEEING KNOWLEDGE AND HISTORY IN PRACTICE
}

\author{
Viv Ellis
}

Accepted with revisions by Mind, Culture, and Activity, March 2010

\author{
Contact: \\ Dr Viv Ellis \\ Oxford Centre for Sociocultural and Activity Theory Research \\ Department of Education \\ University of Oxford \\ 15 Norham Gardens \\ Oxford, OX2 6PY \\ UK \\ Tel: + 441865274009 \\ Fax: +44 1865274027 \\ E-mail: viv.ellis@education.ox.ac.uk
}

\begin{abstract}
:
This article offers a critical examination of aspects of a practice- and theory-developing intervention in the teacher education setting in England designed as a variation of Developmental Work Research. A positive case is argued for the distinctiveness of such CHAT-informed interventions and some points of contrast are drawn with the British tradition of educational action research. In describing the practice-developing intervention, the twin focus on seeing knowledge and history in human activity systems is advanced as two dimensions of CHAT's distinctive approach, with the goal of stimulating and studying the emergence of professional creativity. Creativity under this interpretation is defined as the perception and analysis of opportunities for learning within the social situation of development and the production of new conceptual tools and approaches to the social organisation of work. Professional creativity is advanced as a much needed capacity among teachers in industrial workplaces influenced by the techniques of New Public Management. Common ground between CHAT and action research approaches is seen in their optimistic and modernist commitments to progress and CHAT-framed interventions, like action research approaches, are presented as part of an evolving intellectual project.
\end{abstract}

Key words:

$\begin{array}{ccc}\text { Activity theory } & \text { Developmental work research } & \text { Action research } \\ \text { Knowledge } & \text { History } & \text { Teacher education }\end{array}$


The aim of this article is to offer a critical discussion of one approach to the development of professional practice informed by cultural-historical activity theory (CHAT) and to bring out for examination what distinguishes the tradition of CHAT practice- and theory-developing research from the constellation of approaches to practitioner and participatory inquiry known as action research. In building my argument, I refer to my recent work with CHAT-informed interventions into the organisational learning of schools within a teacher education partnership and I base my comments on what I see as the distinctiveness of the CHAT line by referring, briefly, to the British tradition of educational action research. However, in writing this article, I have tried to maintain the aim of presenting a positive argument for the potential of CHAT-informed, formative interventions into practice rather than seeking to compare CHAT and action research on terms dictated by CHAT. My goal is not for one perspective or the other to become labelled either as enlightened or naïve but to clarify what constitutes the potential of formative interventions into practice from a Vygotskian, activity-theoretical perspective.

The article's title alludes to the moral and political context for the social science practice it discusses. My research has taken place in the very specific setting of England through thirteen years of public service reforms characterised by the techniques of New Public Management (NPM), as defined by Hood (1991) and McLaughlin (2002). The New Labour government's education policy priorities throughout this period have sought to re-make institutional structures, classroom teaching and learning, and the cultural identity of the teaching profession through the application of core NPM techniques such as the specification of behavioural outcomes, the use of Standards as performance criteria, and the introduction or 
extension of competition and markets between 'providers' of public services such as schooling. For Evetts (2009), the consequences of NPM as a modality of public service reform for professionals such as teachers have been profound and have led her to distinguish between two ideal types of professionalism - organisational and occupational. Organisational professionalism is characterised by the delivery of standardised procedures within hierarchical discourses of control with participants subject to external regulation and accountability. Occupational professionalism is characterised by the exercise of judgement and collective reason within local and collegial structures built on trust and subject to ethical accountability by occupational associations.

The implications for professionals' knowledge and how such knowledge is accessed and developed across these two ideal types of professionalism are equally profound, however. The expectation for school teachers within occupational forms of professionalism is for them to be knowledge-workers and to be able to interpret complex social situations such as classrooms and to be able to respond to them flexibly with new ideas and solutions. I am interpreting this capacity, after Vygotsky, as a form of creativity - professional creativity - where, on the basis of 'mastery of concepts' (Vygotsky 1994: 269), the teacher 'imagines, combines, alters and creates something new' (Vygotsky 2004: 10) within the social situation of development. In accepting Evetts' categorisations and their implications for school teaching as knowledge-work, I am suggesting that recent reforms have sought to re-make teaching as a profession on organisational lines without shared, local responsibilities to develop knowledge in practice and without expectations of professional creativity. Like Evetts, I believe this represents an historical shift and, as such, may be re- 
thought and another ideal worked towards. Consequently, stimulating - or reenergising - professional creativity becomes a motive for my work as a teacher educator/researcher and the use of the CHAT tool-kit in developing practice while developing theory.

The attention I give to action research in discussing the re-energising of teachers' and teacher educators' professional creativity, however, is timely and also somewhat ironic. NPM educational reforms in England have not been entirely successful, even on their own terms (e.g. the raising of test scores or the meeting of targets). Evaluative reports both from the government's inspectors (e.g. Ofsted 2009) and from independent, research-informed surveys (e.g. Alexander et al 2009) have questioned the outcomes of the reforms and the modalities of the reforms themselves. In response, some of the reforms' key architects have proposed action research approaches to facilitate innovation and the 'spread' of 'best practice' in what is now referred to as the 'second phase' of reform (e.g. Barber 2009, Hopkins 2005). Somekh and Zeichner have identified this strategy as one type of appropriation of action research by policy-makers - co-option in the service of reform (Somekh \& Zeichner 2009). However, my argument in this article is wider than recent co-options of action research in the service of NPM: it is that CHAT-informed interventions into professional practice have potential because they directly address how professional knowledge is accessed and developed and they also actively seek a historicised understanding of how professional practices have been shaped. To develop my argument, I begin by describing my recent CHAT-informed intervention in the teacher education setting - the DETAIL project. 


\section{DEVELOPING PROFESSIONAL PRACTICE FROM A CHAT}

\section{PERSPECTIVE}

The Developing English Teaching and Internship Learning project (DETAIL) took place in the context of pre-service teacher education at the graduate-level in England. Four secondary school English departments came together to work with me as a teacher educator/researcher to make a deliberate break with the existing design for a teacher education programme by introducing new ideas and ways of working with the aim of making a qualitative improvement to the system (see Ellis 2010, 2008, 2007a for further discussion of the research). The project was designed as a participatory, formative intervention within the cultural-historical tradition and, specifically, as a variation of the Developmental Work Research (DWR) methodology elaborated by Engeström over the last twenty years. DWR has been presented as the 'testbench' (Engeström 1993) of activity theory and as a means of developing practice at the same time as developing the theory of activity. The attraction of DWR to me as an educational researcher, therefore, has been its fundamental questioning of the boundary between 'theoretical' and 'applied' research - particularly problematic border country for those of us who work in the field of Education - as well as its continuing commitment to the Vygotskian developmental project.

I describe the methodology of the DETAIL project as a variation of DWR for several reasons, and I base these comments on Engeström's recent explanation of the methodology in the Cambridge Companion to Vygotsky (Engeström 2007a). The first reason that DETAIL may be described as a variation of DWR is that I was a participant in the teacher education activity systems under study as a university lecturer and researcher rather than an external consultant employed to facilitate 
organisational change; secondly, I did not, for various pragmatic and ethical reasons, generate video data for analysis; third, at more than two years in duration, the DETAIL intervention ran for longer than the usual interventions in Engeström's research centre. However, in working with participants towards the development of professional practice using the conceptual tools of third generation activity theory over time, I believe DETAIL can reasonably be described as a variation of DWR, not least because of the use of activity theory within a double stimulation strategy (c.f. Vygotsky 1978, 1999).

\section{Background to DETAIL}

Pre-service teacher education at the graduate level in England has been essentially school-based (24 out of 36 weeks) since 1992 and English universities are obliged to form partnerships with schools within which the schools provide opportunities to practice and work-place mentoring and the universities provide an academic programme leading to a qualification (the Postgraduate Certificate of Education PGCE) and overall quality assurance. These teacher education partnerships might be interpreted as 'hybrid organisations' (Pirkkalainen \& Kaatrakoski 2007) in that they are occasions for joint work by constituent organisations (schools and universities) that, historically, have developed quite different and potentially contradictory objects, tools and divisions of labour. One of my interests as a researcher in designing the DETAIL intervention was to study the process by which a shared object within such a hybrid organisation might emerge in negotiations and exchanges in the mediating social space of the DWR. 
All of the secondary school English departments within an existing teacher education partnership were invited to take part in DETAIL and six volunteered initially. Two departments subsequently withdrew when senior managers in the schools decided that their participation would be 'disruptive' - disruptive both in the sense of interrupting existing practices and being potentially transgressive culturally. The invitation to the departments was to participate in a project that would both develop teacher education practices in the partnership and develop the practices of English teaching in the schools. For this reason - the dual emphasis on student teacher (or intern) learning and pupil learning in school - the project became known as DETAIL. Each of the four participating departments was asked to identify a problem of professional practice that it wished to work on, something that was meaningful to the teachers in the department on their own terms and that would form the basis for some change-oriented work with the pre-service teachers and myself as teacher educator/researcher. The process of building relationships with the schools and generating suitable practical problems or questions took the best part of a year and a formal series of participatory data analysis workshops - known as 'Change Laboratories' by Engeström (2007a) - began the following year when a new group of sixteen student teachers (four of whom were placed in each of the four participating departments) joined the PGCE course.

Two types of Change Laboratory were organised that operated at different levels of intensity. One type involved the senior mentor teachers in all four schools and myself, representing the hybrid organisation of the teacher education partnership. These Change Laboratories met approximately every two months for two years (see Ellis 2008 for a discussion of this aspect of the work). The second type involved the teachers in each of the participating English departments, their student teachers and 
myself, representing the subject-based teacher education system in each department. These Change Laboratories took place less frequently, in the second year of the intervention only, and were focused around each department's joint work on the identified problem of practice, work that also became the ground for the student teachers' academic assignments.

In both types of Change Laboratory, data representing current practices in relation to the identified problem (known in DWR as 'mirror data') was generated in the school settings by the student teachers and by a research assistant. These data were scrutinised by the research assistant and myself in order to select items and episodes that foregrounded disturbances, contradictions or tensions in current practices and these selections were then taken into the Change Laboratory situations for joint analysis with the participants using the conceptual tools of activity theory. Such selections from the data included transcripts from lessons observed, interviews with participants, as well as visual images such as scans of documents or photographs of artefacts and situations. Large sheets of paper were used to record participants' emergent understandings of current practices and the evolution of contradictions within those practices over time, and new ideas or tools that might be useful in modelling the future of those practices.

As the intervention progressed, and knowledge was accessed and developed that came to inform new designs for practice, these ideas and actions in turn came to be subject to examination in the Change Laboratory situation through their representations in the mirror data. As such, these ideas-driven designs were not offered as solutions in absolute terms - or as definitive 'answers' to the problem of practice - but as partial 
and contingent visions for the future of the practices under examination, a creative process Engeström refers to as a cycle of expansive learning. For my own purposes as a teacher educator and researcher, I conceptualised the Change Laboratory situation as a mediating communicative space through which teachers' professional creativity might be stimulated and studied. I defined professional creativity, after Vygotsky $(1978,1994,2004)$, as the capacity to respond to complex and changing situations and come up with new ideas and solutions. Creativity in this interpretation is the integration of perception and analysis with innovation and production at the level of new social patterns, concepts and material artefacts. It is about engaging with one's social situation of development and responding to it with new ideas.

Vygotsky's later papers on creativity delineate developmental distinctions between childhood, adolescent and adult creativity but, overall, build an argument for the importance of the imagination in all forms of intellectual activity. For Vygotsky, 'imagination was conscious, concrete, and - especially after childhood interdependent with thinking in concepts and reasoning' (Ayman-Nolley 1992: 82). As such, creativity could only be identified or 'labelled' in relation to existing domains of concepts or discourses or ways of reasoning. Indeed, Vygotsky suggested that it was the growth of conceptual understanding through adolescence that set the ground for mature creativity:

For the first time the formation of concepts brings with it a release from the concrete situation and a likelihood of a creative reworking and transformation of its elements (Vygotsky 1994: 276) 
More recent interests in creativity across the social sciences have come to emphasise the social processes by which variations and innovations can be identified as creative. In particular, Sternberg (e.g. 1988, Sternberg \& Lubart 1999) and Csikszentmihalyi (1988) proposed a systems view of creativity that sought to answer the question 'where is creativity?' Csikszentmihalyi's research suggested that creativity was a potential outcome of three 'shaping forces': a field (or set of social institutions) that evaluates individual variations; a cultural domain of symbol systems within which new ideas are taken up; and the individual whose agentic participation within the specific symbol systems might be evaluated as creative by the field (Csikszentmihalyi 1988: 325). There are important distinctions to be made between Vygotsky's ideas of creativity and human development and late twentieth century understandings of creativity in organisational psychology, sociological theory and other disciplines. But the sense in which I am using professional creativity in this article draws on some complementary insights from Vygotsky and from more recent social science, insights that have been summarised by Miettinen (2006) as:

First, the foundation and the starting point for creativity are the existing cultural resources (knowledge, instruments, practices, problems) of a domain. Second, the field recognises, selects and retains the new variants or the contributions of a domain (Miettinen 2006: $174-175)$

Stimulating and studying the creativity of professional groups such as teachers must therefore involve paying attention to activity within specific social and historical contexts. It also, however, acknowledges the field within which such activity occurs and, by implication, holds out the prospect of the strengthening of that field. 


\section{Stimulating change through the analysis of contradictions: the emergence of professional creativity in DETAIL}

Of the four participating English departments, two have been chosen as examples of the stimulation of professional creativity through the perception and analysis of contradictions in data representing their current practices. These two departments known here as Northtown School and Southtown School - responded in a particularly engaged and excited fashion to the intervention and, through the mediation of the activity theory tools in the Change Laboratories, could see potential for the new and qualitatively different forms of activity they were envisioning (see Ellis 2010, 2007a). Northtown School English department chose the teaching and learning of writing as their problem of practice and Southtown School English department chose the teaching and learning of reading as theirs, specifically the teaching and learning of extended literary texts.

\section{Northtown English department: writing and genre}

In the Northtown School English department, the teachers were already aware that they were over-using what they referred to as 'writing frames'. Writing frames are pedagogic tools popularised in England by literacy educators Lewis \& Wray (1995), based on (Australian) genre theory (e.g. Cope \& Kalantzis 1993), and are intended to provide learners with the discourse structure (openings of sentences, key conjunctions, paragraph transitions, etc) of unfamiliar genres of writing. Writing frames and genre-based approaches were also heavily promoted by the government for literacy and English teaching in England, from 1999, approaches in which all teachers were trained by regional consultants (c.f. DfES 1998; DfEE 2001). Over the 
intervention period in the second year of the study, the English teachers at Northtown School became conscious of at least two levels of contradiction in their current practices associated with writing frames. The first - and primary - contradiction was concerned with the use of the writing frame as a mediating tool (enabling pupils to develop familiarity with new genres) and the use of writing frames as a rule or behavioural norm within the department activity system. Writing-frame-as-rule had evolved in relation to increased performance management of teachers and datatracking of individual teachers by school management: teachers were held accountable for their pupils' examination results and year-on-year increases were expected. As one teacher perceived the situation:

You know you have all these children who are supposed to get all these levels, and then you get a nice little percentage where how many of them actually get ... it is a nightmare [Change Laboratory 7 , lines $719-721]$

The use of writing frames had evolved as an aspect of teachers seeking to minimise the risk of their pupils' attaining a low grade and maximising the 'nice little percentage'. In fact, as the intervention progressed, the teachers came to see how the universal application of writing frames came to limit their pupils' level of attainment.

A secondary contradiction was also identified in that the type of 'writing frame' the Northtown School English department was using was not a writing frame at all but rather a very detailed plan, paragraph by paragraph, of what the pupils should be writing. The 'writing frame' was therefore a kind of crib sheet provided by the teacher and often led to the production of almost identical pieces of writing among an entire 
class of pupils. This kind of 'writing frame' therefore came to be understood by the Northtown School English teachers in the Change Laboratories as a superficial appropriation of the writing frame as a pedagogic tool, under-pinned by a restricted understanding of the concept of genre. This conscious awareness was not at the individualistic level of blaming each other as teachers but at the level of collectively understanding the material conditions for their work within a culture of performance management and policy-level expectations of the simple transfer of governmentrecommended classroom routines from scripted training.

In responding to their analysis of these contradictions, the teachers accessed and developed two meaningful conceptual tools: one, of genre as a recognisable pattern of interaction rather than a recipe; two, of scaffolding as a temporary and contingent social relationship rather than an objectified structure. In turn, this process of conceptual growth within the department activity system led to the production of two new pedagogic approaches or ways of organising the social worlds of their classrooms: first, a focus on helping pupils understand the audience for unfamiliar genres through drama games; second, a focus on pupils independently planning the stages in their written texts following the modelling of this process by the teacher. The teachers in Northtown English department saw the future potential in these ideas while simultaneously anticipating obstacles to their embodiment in practices and it was this process of conceptually understanding and responding to actual (current) and potential (future) contradictions that for me constituted an example of professional creativity. 
The focus for the collaborative inquiry at the Southtown School English department grew out of the teachers' concerns that the teaching and learning of reading in their classrooms had shifted in response to recent policy initiatives and the associated national training away from working with pupils to read whole texts (novels, short stories, plays, long poems) towards reading extracts and very short texts, selected to illustrate certain literary or linguistic features. For many of the teachers in this stable and well-resourced department, the reading of whole literary texts had been one of the aspects of the work of English teaching they had previously enjoyed and found motivating; moreover, the teachers also expressed concern about the potential impact of their current teaching practices on their pupils' capacity to make sense of longer texts and to become independent readers. Through an examination of mirror data in the Change Laboratories, the teachers came to understand the patterns of interaction around literary texts in their classrooms as restricted and developed insight into how they had interpreted recent advice from government policy documents and training (e.g. DfES 2001). Moreover, they also reflected on how their current practices and patterns of classroom interaction differed from their historical practices (their ways of working more than five years previously) and so the perception and analysis of the contradictions within their activity system was supported by a subjectively felt memory of how things used to be. Through an examination of the teachers' accounts of their historical practices and from the contributions of the student teacher interns who had both helped to generate mirror data and suggested some good ideas encountered in their teacher education programme - the Southtown School English department introduced the new pedagogic tool of 'literature circles' - as described by Daniels (1994) - and associated approaches to developing independence and criticality in young people as readers. Literature circles have been conceptualised as a means of 
scaffolding readers into the habits, dispositions, roles and forms of discourse of literary discussion, through which pupils 'set their own goals, pursue their own questions, conduct their own inquiries' (Daniels 1994: 10; see also Miller 2003).

As literature circles were being introduced into the ways of teaching and learning reading at the school, data representing the teachers' evolving practices were brought back into the Change Laboratory situation for examination. Once again, a primary contradiction concerning the use-value and exchange-value of the new mediating tool of literature circles was identified: literature circles as a means of supporting and developing independence in literary discussion was in tension with the use of literature circles as a way of aligning with policy over what the government guidance referred to as 'guided reading' (DfES 2001). Guided reading was a nationally specified teaching routine that involved the explicit teaching of certain skills, or ways of responding to texts, to pupils in small groups. A secondary and more conceptual contradiction concerned understanding literature circles merely as a means of organising reading in small groups in classrooms (an understanding we might refer to as a superficial appropriation of the tool, one that, in effect, again becomes a set of rules or normative conventions) versus an understanding of the literature circles pedagogic tool as a means of mediating the habits, dispositions, roles and forms of discourse of literary discussion in pupils' learning (a deeper and more complex appropriation).

In seeking to trace the evolution of the new tool of literature circles in the emergence of new ways of organising the social worlds of the Southtown School's English classrooms, the uncovering of these contradictions for examination through the DWR 
methodology was a stimulus for further learning among the teachers and myself as teacher educator/researcher. In part, this learning was stimulated by an analysis of the classroom discourse and the discourse of the Change Laboratories but it was also invigorated by an investigation of the material artefacts available to the teachers in mediating their pupils' learning. A thorough inventory of English department stock by the student teachers produced several dusty boxes of books and laminated worksheets pushed to the back of cupboards, long forgotten by most of the teachers. These boxes and worksheets revealed themselves to be traces of a much earlier attempt by the Southtown English department to develop pupils' independent reading. Recognising these material artefacts as historical evidence of collective work on potentially the same object led to an important conceptual distinction on the part of the teachers: the meaning of these dusty relics was not the same as that realised by the literature circles as a tool, as they consisted of teacher-directed small group activities whereas literature circles were concerned with developing understanding of readers' roles, resources and perspectives in literary discussion. In this instance, professional creativity among the Southtown School English department consisted in their ongoing and sometimes troubling re-examination of their historical practices alongside the production of a new tool, the meaning of which was being simultaneously and continually elaborated in relation to the ongoing evolution of their practices. The capacity to 'experience the future', as Engeström (2007b) has put it, an inherently creative capacity, nonetheless arises out of a (in the case of Southtown School English teachers) subjectively-felt, complex understanding of the historical evolution of the present.

\section{KNOWLEDGE AND HISTORY IN PRACTICE-DEVELOPING THEORIES}


CHAT-informed formative interventions, of which the variation of DWR discussed here is just one particular kind, derive from a line of thinking about mind and action that, potentially at least, give some purchase on the social science problem of developing practice. At the core of this potential is CHAT's Marxist-Vygotskian critique of the 'metaphysical spectre' (Scribner 1985a: 199) that is the Cartesian dualism of mind and action. According to Scribner, the seminal contribution of CHAT, therefore, has been:

... that neither mind as such, nor behaviour as such, can be taken as the principal category of analysis in the social and psychological sciences. Rather the theory proposes that the starting point and primary unit of analysis should be culturally organised human activities. (Scribner 1985a: 199)

Thus, the CHAT axiom of the reciprocal nature of the relationship between mind and action sets the practical and theoretical challenge of focusing analysis on knowledge and on history both in accounts of practice and in developing practice. Conceptualising knowledge and history in relation to mind and action results in a richer and potentially more generative understanding of practice and it is to these two concepts I now turn in reflecting on my description of aspects of the DETAIL project.

\section{Knowledge in action/in transforming the object of activity}

A CHAT perspective on developing professional practice understands knowledge as accessed and developed in joint work on a potentially shared object. Consequently, knowledge can be understood as existing as much among participants in the same field of practice as it does within them and that the creation of professional knowledge 
(at the level of concepts and patterns of social organisation) might take place in the transformation of the object of activity (c.f. Ellis 2007b), Furthermore, the creation of new concepts, artefacts or patterns of organising joint activity in the settings for practice is understood as having a 'subterranean' trajectory of development (Engeström 2007b) that while expansive or transformational is also very difficult to trace. In the DETAIL project, new ways of organising the activities of teaching writing and teaching reading in the Southtown and Northtown School English classrooms emerged through the surfacing of conceptual understandings and distinctions in the Change Laboratory situations. In Vygotskian terms, the process of stimulating change was occasioned through enabling participant teachers' scientific understandings of their practices through the mediation of the conceptual tools of activity theory. However, the aim of the collaborative work of participants and myself as researcher was not merely a scientific conceptualisation of practice enabled by an upward movement from the (implicitly, lesser) spontaneous 'everyday', but a mature understanding of practice which entailed pushing the knowledge that had been accessed and developed out into the social world of classrooms to do some work. Part of the difficulty of tracing such potentially qualitative transformations of activity systems lies in the ongoing reconstruction of the object of the activity system where participants' efforts to understand 'what are we working on and why?' might potentially lead to a profoundly re-configured landscape for practice and for the questions and problematics that drive both participants' and researchers' interests. At this point, a brief point of contrast with the action research perspective might be illustrative.

Knowledge in the British tradition of Educational Action Research 
Epistemologically, there are several different emphases apparent in the British tradition of educational action research, and some of these emphases have grown into movements associated with different universities and teacher-as-researcher groups. For example, John Elliott and his colleagues at the University of East Anglia asserted that 'the fundamental aim of action research is to improve practice rather than to produce knowledge' (Elliott 1991: 49). Another emphasis was concerned with the reinterpretation of theory (big $\mathrm{T}$ ) as an individual, personal theory of selfimprovement (small t) (e.g. Whitehead 1987, 1988, and colleagues then at the University of Bath) and in this way to bridge a perceived theory-practice divide. Another emphasis that became more international showed the influence of critical social theory in aiming for the emancipation of individuals and groups (e.g. Carr \& Kemmis 1986). Perhaps overall, however, it is possible to say that the British tradition shows the early influence of Kurt Lewin (1946) in its cyclical model of action and its socially liberal commitments but that it is also overlaid with the 'reflective practitioner' stance of Schön (1983) that locates the potential for change within the individual practitioner and distinguishes between 'ordinary practical knowledge' and other kinds of knowledge within an 'epistemology of practice' (p. 113). 'Practical knowledge' - the kind of knowledge with which Schön was concerned - is the kind of knowledge that underpinned the British tradition of educational action research and its rejection of 'theory' reflects this stance. One might speculate that this rejection is associated with a peculiarly anglophone tradition of anti-intellectualism (cf. Heyck 1998, Jones 1996) but the rejection of processes of abstraction and conceptual understanding is often explicit. Thus, Elliott (1991) writes that action research is not concerned with producing 'knowledge' (p. 49) - meaning concepts that have value wider than in the immediate settings for practice - and asserted that university 
education lecturers who were deploying action research methodologies were guilty of ‘academic imperialism' (p. 14).

The action research perspective on teachers' knowledge and learning therefore allows for a certain kind of knowledge to be developed in practice and, to an extent, through interactions. This sort of knowledge is referred to as 'practical knowledge' and is distinguished from other kinds of knowledge that have wider value in the sense of disciplinary or scientific knowledge (characterised, we might say, by ideas that can travel). This latter form of knowledge is just 'out there' from the action research/reflective perspective; traditionally, action researchers attempt no explanation of how concepts are accessed or are developed. So although some pioneers of action research were interested in 'bridging the traditional divide between educational theory and professional practice' (Whitehead 1988: ix), their underlying conceptions of practice and knowledge were restrictive in appearing to focus on action as behaviour without wishing to deal with the concepts that are both developed in and shape historically evolving practices. More recent developments in the British tradition of educational action research have started to engage with CHAT perspectives on practice but a tendency to make claims for a 'unique kind' of knowledge developed in action research persists (Somekh \& Saunders 2007: 187).

This distinction between 'practical' and other kinds of knowledge has significant practical implications and one of these was identified by Elliott in his discussion of the appropriations of action research. Elliott described some appropriations as 'hijacking' action research 'in the service of technical rationality' where the aim was 'how to control pupils' learning to produce predefined curriculum objectives or 
targets' (Elliott 1991: 52; see also Somekh \& Zeichner 2009). Elliott's identification of the potential of action research to be misused to promote greater efficiency and effectiveness in the delivery of government educational reforms was prescient but he and his colleagues also saw that action research deployed in this way would have little enduring impact. Their reasoning was that unless teachers understood their classrooms and perceived the problems of practice they were addressing, their change-oriented actions would be unlikely to succeed. As Rudduck put it, quoting Stenhouse: 'It is teachers in the end who will change the world of the classroom by understanding it' (Rudduck 1988: 35). My argument is that in the DETAIL project, CHAT offered just such a conceptual tool-kit that was useful in understanding practice and learning to transform it. As Stetsenko and Arievitch have summarised: ... the embeddedness of knowledge in practical transformative engagements with the world, and the inextricable link between practical and theoretical, material and mental, political and intellectual, social and individual - all these principles characterise both the real life history of Vygotskian project and the very gist of a theory developed in it. (Stetsenko \& Arievitch 2004: 60)

So, as distinct from an action research epistemology, CHAT maintains that concepts emerge in everyday interactions and human learning and development involves active engagement with scientific or examined concepts in order to form mature understanding and make progress. Toulmin described knowledge creation as an outcome of 'shared [social] procedures' (Toulmin 1999) and also said that 'our conceptual inheritance was communal' (Toulmin 1972), both insights suggesting both the social and historical evolution of knowledge through collective human activity 
and the importance of accounting for knowledge when addressing questions of the development of practice.

\section{Historicising practice through the identification of sediments and buds}

In presenting DWR as the 'testbench of activity theory', Engeström (1993) drew our attention to the historicity and multi-voicedness of activity systems. These insights suggest why an activity system, such as a group of secondary school English teachers who come together to work on the teaching and learning of reading or writing, is not a 'homogenous entity' (ibid) that unproblematically adopts 'best practice' tabula rasa but instead responds and appropriates from a multiplicity of 'elements, voices and viewpoints':

This multiplicity can be understood in terms of historical layers. An activity system always contains sediments of earlier historical layers, as well as buds or shoots of its possible future. These sediments and buds - historically meaningful differences - are found in the different components of the activity system including the physical tools and mental models of the subjects. They are also found in the actions and object units of the activity. (Engeström 1993: 68)

A CHAT contribution to understanding and developing practice might be described as its analytic attention to change and development in activity systems in relation to culturally and historically evolving channels of practices. To this extent, developing practice from a CHAT perspective involves two meanings of practice: the first, involving the micro-genetic development of practice in specific, local activity systems - a level Scribner (1985b) referred to as the 'history of the development of higher 
psychological functions' (p. 133); the second, the historical evolution of streams of cultural practices within which specific activity settings are situated - the level Scribner described as 'general history' (ibid). For me, the analytic challenge and the formative potential of the CHAT perspective lies in its potential to identify and examine the points of contact - and therefore potential sites of development - between change in specific activity systems and historically evolving channels of sociocultural practice.

Engeström's reference to 'sediments' is apposite given the influence of Marxism on the Vygotskian, CHAT perspective. Laclau, from a post-Marxist standpoint, has taken forward the line of thinking from Husserl, Kant and Marx that poses a dialectical view history as a core concept in understanding change. For Laclau, 'to understand something historically is to refer back to its contingent conditions of emergence' (Laclau 1990: 36). The goal of a post-Marxist historical analysis, therefore, is to reveal the conditions under which the 'origins' of social practices came to be routinised or sedimented and the possible system of alternatives concealed. For Laclau and others (e.g. Laclau \& Mouffe 1985, Rancière 1991), the identification of how the origins of apparently objective social situations were concealed is an essential aspect of understanding how hegemonic understandings play out in practices: Insofar as an act of institution has been successful, a 'forgetting of the origins' tends to occur; the system of possible alternatives tends to vanish and the traces of the original contingency tend to fade. In this way, the institution tends to assume the form of a mere objective presence. This is the moment of sedimentation. It is important to realise that this fading entails a concealment. If objectivity is based on 
exclusion, the traces of that exclusion will always somehow be present. (Laclau 1990: 34)

In questioning objectivity as merely 'what is present', Laclau (after Husserl) proposes 'reactivation' as a means of uncovering the exclusions - the possible alternatives that remain at a sedimented level in human activity but are to some extent concealed. However, reactivation does not imply simply returning to the original situation but suggests a process of discovering the 'contingent nature' of the apparently 'objective' present situation through the analysis of tensions within the social field. Laclau reformulates traditional Marxist dialectical materialism with the new concept of 'antagonisms' (which he opposes to systemic contradictions), defined as subjectivelyfelt, situated, ideas-driven differences (Laclau \& Mouffe 1985, Laclau 1990). To extrapolate from Laclau's political science to the CHAT line of thinking about change and development - and building on Engeström's powerful genetic metaphor of sediments and buds - the potential of a formative intervention of a DWR-type can be seen to arise out of its historicising intent with the specific aim of reactivating consciousness of the historically contingent changes in activity systems. In the DETAIL project, for example, uncovering the system of alternatives for the practices of teaching reading in Southtown School English department involved revealing how such alternatives had been concealed (including, in part, physically, through the deep storage of material artefacts) and coming to understand the power of the department's perceptions of NPM educational reforms in constituting current practices, practices revealed as historically contingent. Laclau's re-interpretations of sedimentation and reactivation also foreground the permeable boundary between the social, moral and political dimensions of practice that to a greater or lesser extent underpin CHAT 
accounts of and interventions into practice. In other words, however underplayed in the literature, CHAT practice- and theory-developing interventions reflect an ideological stance committed to modernist ideas of progress. To that extent, at least, CHAT shares a commitment with action research approaches.

\section{CONCLUSION: AN OPTIMISTIC RESPONSE TO REGRET}

In this article I have attempted to outline the potential of CHAT, as I see it, to inform research designs that seek to improve professional practice while theorising it. My comments have been from the perspective of someone working in the field of teacher education and I have referred to a specific example of a formative CHAT intervention into the work of teachers that I conceptualised as a variation of the DWR methodology. In presenting what I believe is the positive case for CHAT-informed interventions in stimulating teachers' professional creativity, at points I have briefly contrasted CHAT designs with action research approaches in order to elaborate on the distinctiveness of CHAT's way of thinking about practice. This distinctiveness, as many have argued, arises out of its critique of the dualism between mind and action. Specifically, I have identified knowledge and history in relation to practice as key, generative, conceptual, 'where to tools' (Engeström 2007b) in methodological terms. My purpose in designing the DETAIL project, as I explained at the beginning of the paper, was to find a way of collaborating with practitioners to support their rethinking of their practices through the development of new cultural tools while, as a researcher, seeking to understand better the development of professional practice and the opportunities for professionals' creativity. To quote Scribner's analysis of dairy warehouse assemblers' knowledge at work, my motive as teacher educator/researcher therefore responded to regret, 'regret that our . . . industrial workplaces' - in this 
case, schools - 'are so organised as to limit the ways in which the thought and action of individual workers can turn back, enrich, and humanise social knowledge and practice' (Scribner 1985a: 206). CHAT-informed interventions might therefore be interpreted as an optimistic or hopeful response to this sort of regret.

In making a positive argument about the potential of CHAT practice- and theorydeveloping interventions, I have tried not to present CHAT (or DWR, specifically) as a solution to the problems of practice. My sense of CHAT's potential from the standpoint of someone involved in the professional practices of teaching and teacher education is inevitably limited by the historical contingencies of these social worlds, something I have argued more generally. Moreover, I recognise that CHAT, and specifically formative interventions in the Marxist-Vygotskian line - whether DWR or not - require further elaboration and critical examination by researchers across multiple disciplines and contexts for practice. As such, CHAT is not a ready-made theory. With reference to my own work in the DETAIL project, at least three substantial limitations suggest the need for further methodological development: first, there seems to me to be an urgent need to understand the relationship between conceptual growth of activity systems in the mediating social space of Change Laboratory-type situations and conceptual growth in the activity settings over time; second, tracing potential trajectories of development in activity systems over the medium to long-term seems an under-researched area and seems to me a significant lacuna in most of the existing CHAT formative interventions; third, DWR, specifically, whether explicitly or not, draws on traditional Marxist and neo-Marxist conceptions of historical change and development, particularly in its emphasis on systemic contradictions and dialectical processes whereas post-Marxist theories of 
social and political conflicts as antagonisms might usefully supplement these emphases and the associated weighting of collective/socially systemic over individual/subjective analysis. Which is to say that a more plural and differentiated understanding of progress and development within competing conditions that are subjectively-felt seems necessary when thinking about change. None of these points are intended to minimise the potential of the CHAT methodological stance that I have been arguing for but instead suggest that CHAT, like action research approaches, is an evolving intellectual project.

Finally, it is worth making explicit the common ground for optimism that CHAT and action research approaches share. In problematising the notion of change through the dialectical method, Laclau poses a challenge for participants in both perspectives concerning the relationship between historical contingency and social progress: 'The future is indeterminate and certainly not guaranteed for us; but that is precisely why it is not lost either' (Laclau 1990: 83). I have argued that by seeing knowledge and history in practice, CHAT offers a distinctive set of tools that might stimulate and reenergise practitioners' creativity, a human capacity that is at the same time conceptual, practical and future-oriented. 


\section{REFERENCES}

Alexander, R. ed. (2009). Children, their World, their Education. Final report and recommendations of the Cambridge Primary Review. London: Routledge; summary and briefing paper available at www.primaryreview.org.uk/downloads/ Finalreport/CWE-briefing.pdf (accessed 20/10/09).

Ayman-Nolley, S. (1992) 'Vygotsky's perspective on the development of imagination and creativity', Creativity Research Journal, 5: 1, 77 - 85.

Barber, M. (2009). 'How a school system should respond to a shrinking budget'. The Guardian, Tuesday $30^{\text {th }}$ June 2009; available at http://www.guardian.co.uk/education/ 2009/jun/30/schools-budgets-funding-cuts (accessed 20/10/09).

Carr, W. \& Kemmis, S. (1986). Becoming Critical. Education, knowledge and action research. Lewes: Falmer Press.

Cope, B. \& Kalantzis, M. (1993) The Powers of Literacy: A Genre Approach to Teaching Writing, Pittsburgh, PA: University of Pittsburgh Press.

Csikszentmihalyi, M. (1988) 'Society, culture, and person: a systems view of creativity', in Sternberg, R.J. ed., The nature of creativity: Contemporary psychological perspectives, Cambridge: Cambridge University Press.

Daniels, H. (1994). Literature Circles: Voice and Choice in the Student-Centred Classroom. Portland, ME: Stenhouse Publishing.

DfEE (Department for Education and Employment) (2001) Framework for Teaching English in Years 7, 8 and 9 (Key Stage 3 National Strategy), London: Author.

DfES (1998b) The National Literacy Strategy: Framework for Teaching, London: Author. 
Elliott, J. (1991). Action Research for Educational Change. Milton Keynes: Open University Press.

Ellis, V. (2010) 'Studying the process of change: The double stimulation strategy in teacher education research', in Ellis, V., Edwards, A. \& Smagorinsky, P. eds. Cultural Historical Perspectives on Teacher Education and Development: Learning Teaching, London \& New York: Routledge.

Ellis, V. (2008) 'Exploring the contradictions in learning to teach: The potential of Developmental Work Research', Changing English: Studies in Culture and Education 16,1: $53-63$.

Ellis, V. (2007a) 'More than "soldiering on": realising the potential of teacher education to rethink English in schools', in Ellis, V., Fox, C. \& Street, B. eds. Rethinking English in Schools: Towards A New and Constructive Stage, London \& New York: Continuum

Ellis, V. (2007b) Subject Knowledge and Teacher Education: The Development of Beginning Teachers' Thinking, London \& New York: Continuum.

Engeström, Y. (2007a). 'Putting activity theory to work: The change laboratory as an application of double stimulation'. In Daniels, H., Cole, M. \& Wertsch, J.V. eds. The Cambridge Companion to Vygotsky. Cambridge \& New York: Cambridge University Press.

Engeström, Y. (2007b). 'Enriching the Theory of Expansive Learning: Lessons from Journeys Towards Coconfiguration'. Mind, Culture, and Activity 14,1: 23 - 39.

Engeström, Y. (2001) 'The Horizontal Dimension of Expansive Learning: Weaving a Texture of Cognitive Trails in the Terrain of Health Care in Helsinki'. Paper presented at the international symposium 'New Challenges to Research on Learning', March 21-23, University of Helsinki, Finland. 
Engeström, Y. (1999) 'Innovative Learning in work teams: analysing cycles of knowlege creation in practice'. In Engeström, Y., Miettinen, R. and Punamaki, R-L, eds. Perspectives on Activity theory, Cambridge \& New York: Cambridge University Press

Engeström, Y., Miettinen, R. and Punamaki, R-L., (eds) (1999) Perspectives on Activity theory, Cambridge \& New York: Cambridge University Press.

Engeström, Y. (1996) 'Developmental work research as educational research: looking ten years back and into the zone of proximal development', Nordisk Pedagogy 16: $131-143$.

Engeström, Y. (1993) 'Developmental work research as a test bench of activity theory: the case of the primary medical care practice', in Chaiklin, S. \& Lave, J. (Eds.) Understanding Practice: Perspectives on activity and context, Cambridge: Cambridge University Press.

Engeström, Y.(1991) 'Developmental Work Research: Reconstructing expertise through expansive learning', In Nurminen, M.I. \& Weir, G.R.S., eds. Human jobs and computer interfaces, Amsterdam \& Oxford: Elsevier.

Engeström, Y. (1987) Learning by expanding: An Activity -Theoretical approach to developmental research, Helsinki: Orienta-Konsultit.

Evetts, J. (2009). 'New professionalism and New Public Management: Changes, Continuities and Consequences'. Comparative Sociology 8 (2009): 247 - 266.

Heyck, T.W. (1998). 'Myths and Meanings of Intellectuals in Twentieth-Century British National Identity’. Journal of British Studies 37 (April): 192 - 221.

Hopkins, D. (2005). Every school a great school. IARTV Seminar Series Paper 146 (August 2005). Jolimont, VIC: IARTV. 
Jones, C. (1996). 'Anti-intellectualism and the peculiarities of British social work education'. In Parton, N. ed. Social theory, social change and social work. (State of Welfare). London: Routledge.

Laclau, E. (1990). New Reflections on the Revolution of Our Time. London: Verso.

Laclau, E. \& Mouffe, C. (1985). Hegemony and Socialist Strategy: Towards a Radical Democratic Politics. London: Verso.

Lewin, K. (1946). 'Action research and minority problems.' Journal of Social Issues 2(1): $34-46$.

Marx, K. \& Engels, F. (1845-6/1964). The German Ideology in Collected Works

Volume 5: Marx and Engels: 1845-47, (S. Ryazanskaya, Trans.), Moscow: Progress Publishers.

McLaughlin, K., Osborne, S.P., \& Ferlie, W. (2002). New Public Management: Current Trends and Future Prospects. London \& New York: Routledge.

McNiff, J. (1988). Action Research: Principles and practice. London: Macmillan.

Miettinen, R. (2006) 'The sources of novelty: A cultural and systemic view of distributed creativity', Creativity and Innovation Management 15,2: 173 - 181.

Miller, S.J. (2003). 'How literature discussion shapes thinking: ZPDs for teaching/learning habits of the heart and mind'. In Kozulin, A., Gindis, B., Ageyev, V. \& Miller, S.M. eds. Vygotsky's Educational Theory in Cultural Context. Cambridge: Cambridge University Press.

Ofsted (2009) English at the crossroads. An evaluation of English in primary and secondary schools 2005 - 2008, London: Author. 
Rancière, J. (1991) The Ignorant Schoolmaster: Five Lessons in Intellectual Emancipation (K. Ross, Intro. \& Trans.), Palo Alto, CA: Stanford University Press.

Rudduck, J. (1988). 'Changing the world of the classroom by understanding it: A review of some aspects of the work of Lawrence Stenhouse', Journal of Curriculum and Supervision 4(1): $30-42$.

Schön, D. (1983). The Reflective Practitioner: How Professionals Think in Action. New York, NY: Basic Books.

Scribner, S. (1985a). 'Knowledge at Work'. Anthropology and Education Quarterly 16,3: $199-206$.

Scribner, S. (1985b). 'Vygotsky's uses of history'. In Wertsch, J.V. ed. Culture and Communication: Vygotskian Perspectives. Cambridge: Cambridge University Press

Somekh, B. \& Zeichner, K. (2009). 'Action research for educational reform: remodelling action research theories and practices in local contexts'. Educational Action Research 17,1: 5- 21.

Somekh, B. \& Saunders, L. (2007) 'Developing knowledge through intervention: meaning and definition of "quality" in research into change', Research Papers in Education 22,1: 183 - 197.

Sternberg, R.J. \& Lubart, T.I. (1999) 'The concept of creativity: prospects and paradigms', in Sternberg, R.J. ed. Handbook of Creativity, Cambridge: Cambridge University Press.

Sternberg, R.J. ed. 1988) The nature of creativity: Contemporary psychological perspectives, Cambridge: Cambridge University Press.

Stetsenko, A. \& Arievitch, I.M. (2004) 'Vygotskian collaborative project of social transformation. History, politics, and practice in knowledge construction', International Journal of Critical Psychology 12 (4), 58-80. 
Toulmin, S. (1999) 'Knowledge as shared procedures', in Engeström, Y., Miettinen, R. \& Punamäki, R. (eds.) Perspectives on activity theory, Cambridge: Cambridge University Press.

Toulmin, S. (1972) Human Understanding. Volume 1: General Introduction and Part 1, Oxford: Clarendon Press.

Vygotsky, L. S. (1978) Mind in society: The development of higher psychological processes (M. Cole, V. John-Steiner, S. Scribner, \& E. Souberman, Eds.).

Cambridge, MA: Harvard University Press.

Vygotsky, L. S. (1986). Thought and language. (A. Kozulin, Ed. \& Trans.).

Cambridge, MA: MIT Press.

Vygotsky, L.S. (1994) 'Imagination and the creativity of the adolescent' (T. Prout \& R. van der Veer, Trans.), in Van der Veer R. \& Valsiner, J. eds. The Vygotsky Reader, Oxford: Blackwell.

Vygotsky, L.S. (2004) 'Imagination and Creativity in Childhood' (M.E. Sharpe Inc., Trans.), Journal of Russian and East European Psychology 42, 1: 7 - 97.

Whitehead, J. (1988). 'Foreword'. In McNiff, J. Action Research: Principles and practice. London: Macmillan.

Whitehead, J. (1987). 'Action research and the politics of educational knowledge'. British Educational Research Journal 13(2): 47 - 63. 